\title{
VIOLÊNCIA, SOCIEDADE E ESCOLA: DA RECUSA DO DIÁlOGO À FALÊNCIA DA PALAVRA
}

\author{
Érika Cecília Soares Oliveira \\ Universidade Estadual Paulista, Bauru, Brasil \\ Sueli Terezinha Ferreira Martins \\ Universidade Estadual Paulista, Botucatu, Brasil
}

\begin{abstract}
RESUMO: Esse artigo aborda a violência na sociedade capitalista e na escola, permitindo uma discussão sobre como ela é veiculada pelos meios de comunicação e pela maneira como os professores a enfrentam. Enfoca a necessidade da comunicação e aponta as dificuldades vivenciadas na construção do indivíduo, do aluno em particular, quando a escola e o professor não possuem clareza da importância da comunicação como forma de simbolização e representação que, em muitos casos, permitem que os atos violentos possam ser substituídos pela palavra. A escola é um lugar privilegiado para a palavra e denúncia de um problema social. Ao se desejar eliminar a violência, acaba-se por naturalizá-la, através das banalizações sofridas pelos meios de comunicação e de um Estado que legitima e violenta seus cidadãos em seus direitos básicos.
\end{abstract}

PALAVRAS-CHAVE: violência; agressão; sociedade; escola; meios de comunicação.

\section{VIOLENCE, SOCIETY AND SCHOOL: FROM REFUSING TO DIALOGUE TO THE FAILURE OF WORDS}

ABSTRACT: This article addresses violence in capitalist society and in school, discussing on how it's published on the media and how teachers deal with it. Considering the students at matter, this paper focuses on the need of communication and the difficulties lived by these developing individuals, in a situation where the school and the teacher don't possess clarity of the importance of communication as a form of symbolization and representation. In many cases, they allow violent actions to be substituted by words. School environment is a privileged place for words and revealing social problems. With the desire to eliminate violence, the media and the State end up naturalizing it, by impinging violence as something trivial and legitimizing violence while violating its citizen's basic rights, respectively. KEYWORDS: violence; aggression; society; school; media.

A construção da subjetividade humana e a vivência do homem em sociedade permitem desvelar algumas hipóteses sobre a questão da violência, considerando-a não um produto exclusivo da sociedade contemporânea, mas algo que atualmente vem se asseverando, possuindo um caráter mais brutal diante de nossas vidas. $\mathrm{O}$ modo como esse fenômeno se expressa atualmente, aponta para a constatação da ausência da palavra, ausência do diálogo e de uma visão crítica, seja por parte de quem assiste ou de quem vivencia a violência. A escola, a família e os meios de comunicação teriam função extremamente importante na abertura deste diálogo, mas à medida que as duas primeiras se calam e os meios de comunicação não param de falar de maneira sensacionalista, a cultura da revolta diante do que choca, do que deveria espantar, transforma-se em cultura do show e do entretenimento. Deste modo, fazem padecer a palavra cuja função é interpelar e procurar respostas e soluções para um fenômeno que fragiliza as tentativas de uma efetiva democratização do país, em que os direitos civis básicos não são assegurados, de forma a violentar o sujeito na tentativa de construir-se como cidadão.

Ao invés do questionamento e da interrogação, o que temos é uma grande parcela da população indiferente ou com medo e até mesmo conivente com práticas que usam da violência com o intuito de "apaziguar", justificando uma ação violenta com outra ação violenta (como no consentimento velado, por parte da população, diante do tratamento cruel que alguns policiais dão aos que transgridem a lei - os "bandidos" - ou ainda com o assentimento dos "justiceiros" em suas ações). Discutir a questão da violência neste artigo implica em inscrevê-la como algo que existe, causa revolta e não merece complacência, ou seja, como um sintoma social e subjetivo, com o qual não se pretende travar pactos de silêncio.

Violência vem do latim, violentia e significa força violenta; ou, ainda, recurso à força, para submeter alguém (contra sua vontade); exercício da força, praticado contra o direito (Russ, 1994). Essa força é definida como violência quando perturba acordos e regras que pautam as relações, o que lhe confere uma carga negativa (Zaluar, 2000). A violência contra o ser humano faz parte de uma trama antiga e complexa: antiga, porque data de séculos as várias formas de violência perpetradas pelo homem e no próprio homem; complexa por tratar-se de um fenômeno intrincado, multifacetado. A análise do fenômeno da violência deve partir do reconhecimento da sua complexidade, abar- 
cando tanto a existência de múltiplas formas de violência, com suas diferenças qualitativas, como também os diferentes níveis de significação e os seus diversos efeitos históricos (Candau, 2001; Martín-Baró,1983/1997).

Iremos nos deter, num primeiro momento, na abordagem de uma violência considerada maior, mantenedora das diversas formas de violência e, portanto, do mal-estar que se espalha pela sociedade. A amplitude da violência, pensada aqui como espaços de sua expressão, vai muito além da instituição familiar (que é vista como um reflexo dessa violência maior), encontrando-se inserida em exercícios de autoridade que ultrapassam os limites legais e que são socialmente aceitáveis, pois são legitimados pelo Estado.

A complexa rede de violência social pode ser vista na díade dominação-exploração que, segundo Saffioti (1989), se estabelece nas relações assimétricas baseadas no conceito de patriarcado-capitalismo-racismo, em que a dominação e a exploração visam pautar todas essas relações, conferindo-lhes a marca da desigualdade. A tríade patriarcado-capitalismo-racismo tem na desigualdade das relações sociais seus atores: a mulher e a criança são inferiores ao homem, o pobre inferior ao rico e o negro inferior ao branco (Saffioti). Estamos, portanto, descrevendo uma sociedade que está longe de ser igualitária, uma sociedade sexista, adultocêntrica, etnocêntrica e classista, na qual o poder de dominar e explorar define o caráter hierárquico das relações sociais e interpessoais.

Nesta rede de poderes encontramos o que foi denominado por Azevedo e Guerra (1989) como "Síndrome do Pequeno Poder", que engendra os processos de dominaçãoexploração interpessoais. O pequeno poder é caracterizado pela sua própria pequenez, pela sua mesquinhez, atuando apenas nas relações interpessoais (Saffioti, 1989, p. 19):

O homem detentor do pequeno poder crê ser necessário exercitar-se, a fim de, algum dia, vir a encarnar plenamente a figura do macho todo-poderoso. Mais do que isto, acredita capacitar-se para o grande exercício do grande poder tendo síndromes sucessivas de pequeno poder. Na verdade, a exorbitância do pequeno poder, característica da síndrome, revela a extrema fragilidade de seu ator. Ao tentar agigantar seu poder não faz senão apequená-lo ainda mais. Entretanto, a síndrome do pequeno poder tem conseqüências nefastas para as pessoas por ela atingidas.

Assim, é possível observar, por exemplo, o aumento da intolerância com relação as diferentes etnias, posto que o padrão hegemônico prevê o "homem branco no poder", desembocando em abusos de poder e atos de violência, como o dos "carecas" que espancam homossexuais e nordestinos ou os "neonazistas" com seus ideais arianos, que deflagram o racismo existente e a inoperância diante do que lhe é diferente.

\section{Violência, Agressão e Sociedade \\ ... que muitas coisas ainda haveríamos de calar e que nessa envoltura é que estaria o dizer..}

(Hilda Hilst: Tu não te moves de ti).

A violência abarca e é abarcada por diversas esferas: social, econômica, cultural, política etc., daí não ser possível indicar uma única esfera como causadora da mesma. Aqui, enfatizaremos a contribuição que o Estado dá na criação e manutenção de diversas violências ao se ausentar e delegar suas responsabilidades à sociedade civil, proporcionando ainda mais a marginalização das pessoas pobres e dos miseráveis. Trata-se, portanto, de um recorte feito para se analisar essa problemática, contudo, não colocamos de lado a abrangência do tema, como bem enfatiza Fraser (2001, p. 95):

\begin{abstract}
A delinqüência e a violência são, pois, sintomas sociais de grande amplitude, onde vários fatores se entrelaçam, não podendo ser arbitrariamente atribuídos ao fator econômico como determinante da pobreza e responsável por todas as mazelas sociais, pois explicar o crime pela pobreza é, além de tudo, reforçar a opção preferencial pelos pobres, como se a criminalidade fosse um privilégio destes.
\end{abstract}

Para avançarmos nesta discussão é importante explicitar uma das principais confusões existentes em relação à terminologia utilizada quando cientistas sociais, psicólogos, meios de comunicação de massa, utilizam os conceitos de violência e agressão. Martín-Baró (1983/1997) posiciona-se diferenciando os dois conceitos:

O conceito de violência é mais amplo que o de agres-
são e que, em teoria, todo ato ao que se aplique uma
dose de força excessiva pode ser considerado como
violento. A agressão, por outro lado, somente seria
uma forma de violência: aquela que aplica a força
contra alguém de maneira intencional, ou seja, aque-
la ação mediante a qual se pretende causar um dano
a outra pessoa (p. 365-366).

Existem psicólogos que não caracterizam a agressividade como sendo algo positivo ou negativo, considerandoa como um impulso ou instinto comum ao ser humano e direcionado para a luta, para a sobrevivência individual ou coletiva. Há discussões sobre o caráter biológico da agressividade. Assim, subsidiados pelo evolucionismo darwiniano, muitos psicólogos aceitam o caráter negativo da violência, mas eximem dele a agressão. Consideram que a agressão é a manifestação da agressividade, modo de auto-afirmação do indivíduo. Cotidianamente, constatamos, como apresentado por Martín-Baró (1983/1997), que se fala da necessidade de certa dose de agressividade para que o homem contemporâneo vença os obstáculos do mundo moderno. Muitas vezes "ser agressivo" vem associado com "ser dinâmico", "ser competente", não importando muito o que é preciso fazer para alcançar o patamar 
do chamado "cidadão vencedor". Para o autor, os valores que regem a vida cotidiana dos membros da sociedade são o individualismo, que estimula a violência, a agressão como meio de satisfação individual e a competição, na qual o êxito de um implica no fracasso do outro.

Para Martín-Baró (1983/1997), não há necessidade de se procurar as raízes da agressão e da violência dentro das pessoas. A agressão e a violência podem ser encontradas nas circunstâncias em que vivem, atribuindo ao fato das pessoas se verem frustradas em seus desejos e vontades ou, ainda, pelo fato de terem aprendido a alcançar seus objetivos através da utilização da violência, o que confere à agressão e à violência um caráter encontrado e assimilado na sociedade, através das relações entre os indivíduos. São três os pressupostos sobre a violência apresentados pelo autor:

1. "a violência apresenta múltiplas formas e que entre elas podem dar-se diferenças muito importantes" (Martín-Baró, 1983/1997, p. 370). Como exemplos, são citadas: violência estrutural; violência interpessoal; violência educativa; violência pessoal; agressão institucional; agressão interpessoal; agressão física; agressão moral ou simbólica.

2. "a violência tem um caráter histórico e, por conseguinte, é impossível entendê-la fora do contexto social em que se produz" (Martín-Baró, 1983/1997, p. 371), o que significa que é impossível analisá-la sem considerar os interesses e os valores concretos que caracterizam a sociedade ou cada grupo social em determinado momento histórico.

3. refere-se à "espiral de violência", fato continuamente encontrado nos atos de violência social: peso autônomo que os dinamiza e os multiplica.

Para El-Moor e Batista (1999), os fatores imediatos que desencadeiam a violência seriam: a frustração, pressão grupal, disponibilidade de poder e o convencimento sobre seu valor instrumental.

Martín-Baró (1983/1997) diz que em todo ato de violência é necessário diferenciar quatro fatores constitutivos: a estrutura formal do ato - a conduta como forma extrínseca, que pode ser instrumental (utilizado como meio para atingir um objetivo diferente) ou terminal/final (realizado por si mesmo; ato como fim); a "equação pessoal" - atos explicados somente pelo caráter particular da pessoa que o realiza; o contexto possibilitador - contexto amplo, social, e um contexto imediato, situacional; o fundo ideológico - a violência remete a uma realidade social com interesses de classe, em que surgem valores e racionalizações, levando a sua justificação (p. 372-376).

Com essa ressalva, podemos então considerar a violência como todo ato ao qual se aplique uma dose de força excessiva e a agressão como uma forma de violência (força contra alguém aplicada de maneira intencional, com a pretensão de causar um dano à outra pessoa).

Como fenômeno histórico e social, uma das formas de sua manifestação é a violência estrutural. Ela é a violência do Estado contra o homem, caracterizada pela incapacidade do primeiro em realizar a justiça social para os adultos em geral, e às crianças e adolescentes que são destituídos, implícita ou explicitamente, do acesso à escola, à saúde e à assistência social. Um Estado que deixa parte significativa da população em situação de desemprego, carência, abandono e inúmeras outras iniqüidades é um Estado violentador, agente da opressão e facilitador das realizações da classe dominante. Estado este que abandona a família à sua própria sorte, num regime assistencialista e paternalista, violentando o indivíduo em suas tentativas de exercer sua cidadania (Passetti, 1995). O autor afirma que "o próprio Estado enseja a prática de maus-tratos quando não cumpre com as responsabilidades que traça para si mesmo. Consome, proporcionalmente, a maior parte dos impostos pagos pelos cidadãos na sua própria reprodução...” (p. 51). Em termos estruturais, a violência é também uma consequiência do processo de globalização. As políticas distributivas injustas promovem o que se denomina de "incursão na miséria", propiciadora das invasões e saques, da violência urbana, da existência de crianças e jovens sem perspectivas e atolados no consumo de drogas e na delinqüência. Além disso, encontramos a violência ideológica que transforma os sujeitos em objetos, dificultando sua participação nas decisões políticas ao criar e referendar uma cultura que acredita cegamente nos poderes absolutos do Executivo e na chegada de um líder messiânico, que resolverá tudo sem a participação da coletividade.

Martín-Baró (1983/1997) ressalta que a violência estrutural:

não se reduz a uma inadequada distribuição dos recursos disponíveis que impede a satisfação das necessidades básicas das maiorias; a violência estrutural supõe além disso um ordenamento dessa desigualdade opressiva, mediante uma legislação que ampara os mecanismos de distribuição social da riqueza e estabelece uma força coercitiva para fazê-los respeitar. $O$ sistema fecha assim o ciclo de violência justificando e protegendo aquelas estruturas que privilegiam as minorias à custa dos demais (p. 406).

Para o Jornal de Psicologia, (Conselho Regional de Psicologia [CRP], 2000), a violência traz consigo um caráter permanente, e coloca duas questões: ao mesmo tempo em que provoca um estado de freqüente temor, por outro lado, ela se banaliza. Os meios de comunicação apresentam-se como poderosos instrumentos que contribuem e promovem essa banalização da violência, utilizando-se do arsenal de crimes, com o único objetivo de sustentar e aumentar sua audiência como a venda de publicações, le- 
vando a uma diluição, ao esvaziamento do que o conceito de violência implica efetivamente. A banalização da violência pelos meios de comunicação é mencionada também pelos alunos de escola pública que participaram de pesquisa realizada por Candau (2001). A autora chama a atenção para o desenvolvimento de uma cultura da violência, "que se alastra e favorece todo um processo de banalização e naturalização de diferentes formas de violência" (p. 146).

Monteiro (1998) ao realizar uma pesquisa junto aos diretores que passaram pela escola que a autora investigou durante dois anos, obteve os seguintes relatos: para os diretores, a violência estava relacionada com a televisão, o nível sócio-econômico das famílias, a falta de educação e a desestruturação familiar. Relatos semelhantes são encontrados entre os professores que participaram de pesquisa realizada por Candau et al. (citada por Candau, 2001). Para os professores, a violência é um fenômeno que "se origina na sociedade e se reflete na escola, seu dinamismo é de 'fora' para 'dentro"' (p. 142). Deste modo, segundo a autora: "Os/as professores(as), em geral, têm dificuldade de identificar formas de violência geradas pela própria escola, não vêem a cultura escolar como fonte de violência" (p. 142). Outros estudos realizados em escolas apontam para a televisão como um fator desencadeante da violência e por isso nos deteremos um pouco nessa questão (Njaine \& Minayo, 2003).

Os meios de comunicação constroem uma imagem da violência em que essa é eternamente repetida, capturando o indivíduo nessa repetição, sem que haja possibilidade de simbolização por parte deste, ou seja, a violência, como linguagem pode prescindir da violência como ato social, mas isso só é possível, segundo Rocha (2001), quando o indivíduo desalienar-se das imagens que lhe são postas e passar a representá-las. Rocha (2001) e Kehl (2001) abordam o rap como algo que possibilita que o não simbolizado passe a ser representado e se reinscreva no imaginário, o que permite ao indivíduo falar sobre o que acontece, deixando necessariamente de agir de forma violenta.

Existe, por um lado, uma sociedade que procura criar modelos de identidade baseados no glamour, no consumismo e na fantasia, passando a falsa idéia de ascensão social fácil, rápida e possível para todos. Njaine e Minayo (2003), ao realizarem pesquisa sobre violência em escolas públicas e particulares, junto a professores e alunos, relatam que os professores vêem a televisão como um meio que contribui na formação da identidade dos jovens, promovendo esses modelos de ascensão, considerados, como "maus modelos", tais como os artistas, pagodeiros, jogadores de futebol, manequins. Estes modelos preconizam que existe um jeito fácil de se alcançar sucesso, que dispensa o estudo e o trabalho, assim como o de enriquecer fartamente, através das figuras de políticos que ganham fortunas de maneiras ilícitas. Estes seriam os chamados “maus exemplos" na formação da identidade, segundo os professores pesquisados.

Por outro lado, e ainda dentro da mesma sociedade, existe a tentativa de construção de uma identidade que procura se defender das ideologias impostas pelos meios de comunicação e na luta para romper com o determinismo colocado por aqueles que postulam que "se é pobre é violento" e, uma vez inserido neste meio, o único caminho é o da criminalidade. Kehl (2001) deixa claro esse processo ao analisar os rappers que apelam, através da liberdade de expressão, para a consciência de cada um e para a criação de valores antagônicos aos construídos pelos meios de comunicação, enfocando a autovalorização e dignidade do negro e pobre. Nas palavras da autora:

$O$ viés autoritário desses versos [letra do rap dos Racionais MC's], a nosso ver, tem pelo menos três determinantes. Primeiro, a certeza de que uma causa coletiva está em jogo. Trata-se de estancar o derramamento de sangue de várias gerações de negros, de barrar a discriminação sem recusar a marca originária... Mas para isto - aí vem a segunda razão - é necessário "transmitir a realidade em si". Isto porque a maior ameaça não vem necessariamente da violência policial, nem da indiferença dos "boys". Vem da mistificação produzida pelos apelos da publicidade, pela confusão entre consumidor e cidadão que se estabeleceu no Brasil neoliberal, que fazem com que o jovem da periferia esqueça sua cultura, desvalorize seus iguais e sua origem, fascinado pelos signos do poder ostentados pelo burguês... (Kehl, 2001, p. 99, grifos nossos).

Evidentemente, há também todo um questionamento a respeito desse poder ostentado pelo burguês, aí alienado no consumismo e no fetiche dos produtos que lhes são ofertados a todo instante, contudo, não desenvolveremos essa discussão neste artigo.

A violência ganha o espaço para o diálogo, desprendendo-se de um monólogo no qual existe uma divisão entre fortes e fracos. Rocha (2001), defende que o papel dos meios de comunicação na estruturação de nossas vidas e o papel da violência na organização de relações de comunicação e sociabilidade encontram-se em um estado de simbiose, em que tanto num caso (meios de comunicação) como no outro (sociedade), ocorre uma ruptura do valor simbólico. No caso da violência que os meios de comunicação veiculam, as informações são transformadas em imagens e sons peculiares, que através de sua velocidade, tornam essas imagens e sons mais pulsantes e presentes, causando, um "desgaste e arrefecimento das sensibilidades", sem, contudo, deixar de atrair a atenção das pessoas, tomando o seu caráter de espetáculo, criando visões estetizadas sobre a violência.

Essa estetização da imagem e a perpetuação da violência discursiva e difundida pela mídia promovem uma des- 
sacralização da imagem e uma ruptura entre o real e a ficção, criando-se um redimensionamento dos fatos. $\mathrm{O}$ aumento da propagação das imagens de violência cria, segundo a autora, uma "promiscuidade" em torno do tema:

A apreensão da violência através de imagens, se não escapa de uma lógica de sedução e do arrebatamento, confere curiosa atribuição ao nosso "estoque" imagético. Cada peça adquirida perde imediatamente seu peso ou valor individual quando é inserida na "coleção". Não costumamos hierarquizar com muita facilidade as 'imagens da violência'. Parece ser mais comum atribuir-se a estas imagens um valor relacional, como se cada uma fosse, na verdade, a parte de um quebra-cabeças, a fração de um mosaico que, a despeito de sua capacidade constante de aglutinação e reestruturação, de seu fracionamento, apresenta-se como unidade (Rocha, 2001, p. 91, grifos nossos).

É importante salientar o fascínio que essas "imagens da violência" carregam, seja por parte de quem as pratica ou de quem as experimenta. Esse fascínio, sedução e arrebatamento, citados pela autora, inviabilizam a reflexão e a fala, daí a necessidade de se apontar para a existência, seja na favela, dos grupos de rap que constroem seu discurso a respeito da realidade vivida e também da família e da escola, como lugares "formadores de valores e opiniões." A discussão sobre a relevância da comunicação, do diálogo e da escuta no espaço escolar será realizada mais adiante.

Porto e Teixeira (1998) demonstram que o temor em relação à violência resulta no poder que a sociedade confere ao Estado para que o mesmo tome medidas cada vez mais autoritárias e punitivas, legitimando o discurso dos políticos, dos religiosos que conferem o aumento da violência e da criminalidade a uma sociedade cuja moral encontra-se decadente. Cria-se um "discurso da ordem" que culpabiliza as famílias desfeitas, a liberação das mulheres, a liberdade sexual, a crise da ética no trabalho, crise da fé religiosa, crise moral. É evidente que alguns destes fatores também podem contribuir para o aumento da violência por si só, contudo, ao se dar livre-arbítrio aos elaboradores e criadores de métodos e alternativas para sanar as práticas sociais violentas, lhes é dado o poder de criarem o que as autoras denominaram de "imaginário da segurança", ou seja, ao nos depararmos com a onda de criminalidade na qual a sociedade está mergulhada, a criação de penitenciárias e Fundações Estaduais de Bem-Estar do Menor (FEBEMs) pode levar à falsa idéia de que a população estará segura em suas casas, pois os supostos "bandidos" estarão presos, longe de poder atacá-las, enquanto dentro dessas instituições muito pouco se propõe em termos de mudanças que farão com que esses indivíduos, ao retornarem à sociedade, não voltem a cometer delito.
No que diz respeito à relação entre pobreza/miséria e violência, El-Moor e Batista (1999) afirmam que a relação não é direta e explicam que o indivíduo está sujeito a humilhações constantes, a discriminações sociais, levando a uma destruição de sua auto-estima. Com sua auto-estima negativa é possível que se construam elementos que permitam uma ponte entre a miséria e a violência. As autoras apontam para uma discussão extremamente relevante para se compreender a complexidade deste assunto: estamos inseridos numa sociedade capitalista cuja instigação ao consumo é desenfreada, incansável e excessiva. A mídia constrói o glamour do mundo dos ricos e a tristeza, a vergonha, a sujeira e a feiúra dos pobres e seus mundos. Nas palavras delas:

Estes últimos [os pobres] estão obrigados a se ver quotidianamente no retrato do que a sociedade... diz que eles são, mas que eles "odeiam”. Ora, a incitação ao consumo num contexto de exclusão (sabemos que os desempregados, pobres, marginalizados, além do discurso por eles esgrimido, a maior parte das vezes acabam se culpando pela situação em que estão), cria no indivíduo sentimentos negativos de si mesmo, o leva à impotência (p. 149).

Freire (1996) denuncia essa culpabilização que o Estado imprime ao pobre, uma vez que faz parte do poder ideológico dominante inculcar a responsabilidade nos oprimidos, por encontrarem-se nessa situação. São pessoas que fazem parte da legião de ofendidos e que desconhecem a razão de sua dor na perversidade do sistema social em que se encontram. A consciência dessa incompetência, segundo o autor, tende apenas a reforçar o poder que os massacra.

Não se trata unicamente de privações materiais que conduzem uma pessoa a desafiar aspectos éticos e morais da sociedade em que vive, na procura, por exemplo, do narcotráfico. Alienados do sistema, os portadores da violência não têm como finalidade promover uma mudança de cunho social, solucionando a vida miserável dos outros. Seus anseios de consumo são individualistas e imediatos. Traduzem a violência "organizada" através do tráfego de drogas, ${ }^{1}$ dos grupos de seqüestro e a violência denominada "não organizada" que se realiza através de roubos, por vezes seguidos de morte da vítima, etc. (El-Moor \& Batista, 1999).

Teixeira (1999) ao pontuar o delito, classifica-o como a expressão mais visível da violência. Segundo a autora, o delito carrega uma "fala" consigo, fala essa que denuncia a precariedade de nossa sociedade. Quando trata do coletivo, refere-se à sociedade que mantém e estimula a criminalidade. Ao falar da singularidade do sujeito que cometeu o delito, a autora aponta para história pessoal dele, as violências a que se sujeitou, a quebra do pacto interno com a lei. O delito, portanto, seria a exposição das 
múltiplas determinações pelas quais o sujeito passa: a distribuição desigual de rendas e de direitos, a precariedade das políticas assistenciais para a criança e o adolescente em situações de risco pessoal, a escola que expulsa, os meios de comunicação que banalizam a violência.

\section{Violência nas Escolas}

A palavra era como um corpo morto que tivesse vindo atravessar-se no seu caminho, tinha de descobrir o que ela queria, levantar o cadáver

(José Saramago em Ensaio sobre a lucidez).

Agressões verbais seguidas de pontapés, socos e mordidas. Esse campo de tensão ao qual o professor diversas vezes vê-se exposto pode levá-lo a fazer um questionamento de sua atividade, que se contradiz entre educar ou reprimir, formar um sujeito independente ou um sujeito comandado. "Mas o que seria educar?", perguntam Pinto e Batista (1999 p. 321). Questionam se educar seria sair dos limites da Língua Portuguesa e da Matemática e adentrar em questões mais amplas do comportamento. Eles acreditam que educar tenha relação com essas questões, mas quando falam de educação não estão se referindo ao ensino de boas maneiras e tampouco nas posturas policialescas que os professores por vezes se vêem compelidos a exercer, colocando em dúvida sua prática como educador.

Como parte do dia-a-dia da escola, a violência é fruto de diversos fatores, tais como a profunda desigualdade entre as classes sociais, a imposição de regras coletivas, a repetição dos modelos que os alunos vivenciam em seus lares. O início da violência se dá através das "possibilidades de sobrevivência” que, para Itani (1998, p. 40), seria assegurar um lugar na escola, seguido da "fragmentação do conhecimento", isto é, a obstrução das possibilidades do domínio do conhecimento e, por fim, o processo educacional violentador se daria pela "ideologização da informação pela ação pedagógica e pela indústria cultural." Além disso, a autora aponta para a violência embutida no sistema educacional (violência simbólica) que se volta contra o professor através da imposição de projetos de formação, projetos educativos e de ações pedagógicas, uma vez que os professores não são consultados no momento da elaboração de tais projetos, que geralmente estão permeados pela ideologia dominante.

A violência que se configura dentro do espaço escolar, manifestada através do comportamento dos alunos, lança professores diante da confusão da possibilidade de um ensino libertador (caso seja esta a sua proposta) e de uma realidade insuportável, na qual os educadores recorrem a expedientes autoritários e até mesmo violentadores, a fim de manter a “ordem geral”. São estabelecidas regras, controles, punições e dominações para disciplinar os alunos em estados de rebeldia.

Sposito (2001), analisando a produção científica nesta área, indica que ocorreram mudanças no padrão da vio- lência no decorrer do tempo. Na década de 1980 eram mais comuns os atos de vandalismo: a violência contra o patrimônio, com as depredações e invasões dos prédios escolares. Na década de 1990, ganham destaque as agressões interpessoais, principalmente entre os alunos. Além disso, se na década de 1980 a violência atingia principalmente as escolas de grandes centros urbanos, na década seguinte ela é encontrada, com muita freqüência, em municípios de médio porte e menos industrializadas.

Para Porto e Teixeira (1998), a violência escolar assume diversas facetas, que podem se configurar na já chamada violência simbólica. Existe ainda, para alguns professores, uma maneira de manter os alunos em silêncio (e isso seria uma espécie de violência simbólica), por exemplo, através de cópias e ditados sem uma intencionalidade pedagógica e, finalmente, nas discriminações e exclusões. Itani (1998) exemplifica como violência simbólica o caráter disciplinador que por vezes é conferido à avaliação, que serve como um instrumento que mede a capacidade do aluno através da exigência de respostas idênticas às formuladas em sala de aula, ou ainda, a execução de provas extremamente difíceis com o intuito de diminuir a nota do aluno. Segundo Fernandes et al. (1999) no sistema escolar vigente, a avaliação é o instrumento que permite premiar o aluno. É através dela que se classifica o aluno como bom ou mau. O responsável, na sala de aula, por esta classificação, é o professor. Perde-se de vista o caráter altamente necessário da avaliação como diagnóstico do processo ensino-aprendizagem.

Ao praticar atos de controle, abafa-se o que a violência está, ferozmente, tentando falar em suas múltiplas manifestações: desde a arquitetura da escola que é detonada pelos alunos até as relações aluno/aluno, aluno/professor e aluno/funcionário são envolvidas pela agressividade e violência.

Diante disso, encontramos um professor impotente diante de seu papel, como observa Perdriault (1989), ao questionar se trata mesmo de um professor ou de um domador de feras. Através da exclusão, alguns professores delegam a questão da violência que ocorre cotidianamente na escola, totalmente à família, abstendo-se da possibilidade de fazer algo a respeito e, sobretudo, tentando livrarse de sua cota de responsabilidade pelo fato de também ser a escola uma reprodutora das relações parentais que envolvem disciplinamento, hierarquia e, em um nível mais velado, da surdez, por vezes estratégica, diante das já citadas manifestações (verbais ou não-verbais), por parte dos atores que compõem o universo escolar.

Os professores sentem-se desorientados diante deste cenário caótico ou então, se colocam numa postura de indiferença, na qual, tanto eles, professores, bem como os alunos, estão sendo violentados diante de suas vontades e necessidades. Nas palavras de Perdriault (1989, p. 82): 
"A escola morre de infantilismo, da falta da palavra, da falta do desejo. A violência do sistema escolar, que tritura adultos e alunos, só pode ser freada pela violência da lei e da palavra."

Apesar de termos claro que a violência na escola não é um fenômeno restrito às escolas de periferia, como indicam vários estudos (Candau, 2001; Sposito, 2001), essas escolas sofrem com a falta de espaço nas salas de aula, espaço vital que contribui para que a população se revolte e ataque as dependências da mesma, sendo que a superpopulação das escolas contribui para o surgimento da violência, através dos descontentamentos que produz. Para Medrado (1998):

a escola não pode responder pelo papel do Estado, oferecendo à população o espaço vital destinado ao lazer, "nem promover" a formação informal da população local, tampouco pode prestar assistência social de que tanto necessitam os marginalizados. Afinal de contas, isto é dever do Estado. E embora saibamos que a escola seja uma pequena "parte" do Estado, ela não pode funcionar como reparador ou substitutos do mesmo (p. 90).

O autor descreve dois problemas de representação: no primeiro, a escola, vista como representante do Estado, terá que assumir as funções do mesmo aos olhos da população. Ela deixará, assim, de exercer sua função, que é a de educar, e passará a exercer outras funções que cabem ao Estado resolver. Temos assim a "escola-assistencialista". Esse papel que algumas escolas assumem é extremamente melindroso, uma vez que se algo não funciona ou se funciona mal no país, a população irá dirigir suas críticas maciçamente à escola e não ao Estado. Outro problema de representação, segundo o autor, encontra-se nos precários recursos (materiais, humanos e financeiros) que não permitem que a população desfrute de seus direitos.

Medrado (1998) contribui para uma discussão muito valiosa que diz respeito ao que ele denomina de "parafernália militar". Para ele, a escola é o espaço destinado para promover a educação e não um lugar para guardar artefatos para proteção. Ele questiona: "Em primeiro lugar, proteção do quê?” Em segundo lugar: “contra quem?” (p. 101). A presença de cães nas escolas, guardas armados, alambrados de ferro, arames farpados, muros altos e, principalmente, a intervenção da polícia através da ronda escolar, são medidas inócuas. Para o autor, além da escola não ser caso de polícia, essa ostentação paramilitar agride o universo interno da mesma, pois os alunos passam a vê-la como um presídio e não como um lugar para o desenvolvimento do exercício de seus direitos e deveres. Para a comunidade, é sentida como um espaço que não lhes pertence, dando a entender que a escola é protegida contra eles, o que faz com que ela seja alvo de ataques.

Na maioria das vezes, a escola não sabe o que fazer diante deste quadro e cada um se sustenta como pode. Os papéis e as responsabilidades ficam fragilizados e comprometidos diante da violência que alunos e professores manifestam e na necessidade e desejo daqueles que, por vezes, não ousam falar ou não praticam o exercício de uma fala significativa.

Como se coloca, então, o papel do ensino e aprendizagem: árduo ou prazeroso? Perdriault (1989) diz: "É difícil falar... mais difícil do que trocar socos." Falar, ouvir e compreender o que está sendo dito nessa linguagem que se manifesta através da violência, que às vezes mais parece coisa de alunos puramente caprichosos; quando, na verdade, o que ocorre é que essa violência tem muito a ver com o discurso da recusa, ou ainda, a ausência de se encontrar as palavras certas para se dar um sentido exato a uma ampla gama de sentimentos.

Segundo Reyzábal (2003) a educação baseia-se na linguagem, que é o que assegura o intercâmbio (participação, perguntas, respostas, esclarecimentos, estímulos, etc.) durante o processo de ensino e aprendizagem e o instrumento que o estudante usa para organizar sua realidade interior e exterior. Neste caso, o diálogo deve ser constante entre docente e discente, já que ambos encarnam duas funções intercambiáveis e mutuamente enriquecedoras.

Antes, contudo, de falarmos da importância da comunicação como possibilidade de representação e simbolização daquilo que não é dito e que se expressa através da violência, também nas escolas, apontaremos para um problema anterior que diz respeito à variedade lingüística, isto é, às diversas línguas e dialetos que o aluno utiliza-se para se expressar e que são cerceados pela escola, por não se tratar da linguagem padrão, prestigiada e sinônimo de poder. Partindo do pressuposto, como nos mostra Camacho (2004), de que toda língua varia e que essa variação é o reflexo de diferenças sociais, como origem geográfica e classe social e de circunstâncias de comunicação, apontaremos para o fato de que, ao não aceitar a linguagem trazida pelo aluno, marginalizando-o e excluindo-o com as normas da Língua Portuguesa Padrão, o professor desconsidera a questão do bidialetalismo, ou seja, o fato de que existem várias línguas e que a que o aluno traz deve ser respeitada. O próprio professor pode destituir o aluno da classe menos favorecida ou o adolescente com suas gírias, de seu direito de expressar-se, calando-o diante da falsa idéia de que existe apenas uma língua correta e que a dele é deficiente e incorreta. Esse já seria um primeiro apontamento quando o assunto é comunicação: todos conseguem se expressar ou podem aprender a expressar o que pensam, desde que haja permissão para isso.

A linguagem oral, contudo, não recebe a mesma atenção que a linguagem escrita nas escolas, havendo uma deficiência no diálogo entre aluno e professor pelo fato de que a linguagem escrita é considerada polida, seleta, literária e a língua falada é tida como sinônimo de língua popular. Mas é através da linguagem oral que o aluno se 
socializa e se relaciona com os demais, organiza seus pensamentos para se fazer entender, adquire a prática para o diálogo e a escuta, sem o que não terá instrumento para participar de uma sociedade que se pretende democrática. A necessidade da utilização da palavra se dá desde a educação infantil. É através da linguagem oral, da palavra, que apontamos, tanto no caso dos rappers como no caso dos alunos e professores (e de todo ser humano) para a possibilidade da mudança, da leitura do mundo que os cerca e da tentativa de expressar aquilo que está internalizado, muitas vezes de forma confusa, como revolta diante das injustiças que sofre ou vê sofrerem, como agressividade que precisa de um canal de saída. Cabe ao adulto, neste caso, o professor, promover a ascensão da palavra, tanto a dele como a do aluno. É evidente que as aulas expositivas - consideradas tradicionais e criticadas por muitos - possuem vários aspectos positivos, mas é preciso atentar para o fato de que usá-las como um expediente no qual se pretende o silêncio e a passividade, é uma contribuição para a morte do desejo e da palavra por parte do aluno.

Existem vários pressupostos e tentativas de solução, mas o que se pode dizer, num primeiro momento, é que a partir do instante em que o professor deixa de tentar dominar a situação e leva em conta a realidade e toda a dificuldade nela inserida, cheia de contradições, é que será possível realizar proposições e elaborações, e assim, a escola passará a representar um outro papel que não será mais o de esperar o futuro e sim o lugar no qual se vive o presente, através da vida e trocas que ele proporciona (Colombier, 1989).

Podemos entrever os desdobramentos que poderiam ser concebidos através da dupla escola/violência: há "a escola da violência" construída pela sociedade que mantém e fomenta a violência estrutural que, por sua vez, difunde as demais formas de violência que os indivíduos vão aprendendo e assimilando em seu cotidiano, ora sutilmente, ora abertamente. Tem-se a "violência na escola" que, como foi demonstrado, acontece através da troca de agressões físicas e verbais entre alunos ou alunos e professores assim como também existe a "violência da escola", a escola como reprodutora da ideologia dominante e das desigualdades sociais, empareda professores e alunos em suas normas, regras e leis, impedindo-os de movimentar-se para direcionarem-se de maneira autônoma e, sobretudo, transformadora. Assim, a escola (sociedade) que ensina e pratica a violência, tem como sua representante a instituição escolar, que vivencia e exerce também suas violências.

\section{Notas}

1 El-Moor e Batista (1999) utilizam-se desta expressão que é sinônimo de tráfico, como significando "fluxo de mercadorias transportadas por aerovia, ferrovia, hidrovia ou rodovia" (Ferreira, 1999, p. 1982).

\section{Referências}

Azevedo, M. A., \& Guerra, V. N. A. (Eds.). (1989). Crianças vitimizadas: A síndrome do pequeno poder. São Paulo, SP: Iglu.

Camacho, R. G. (2004). Norma culta e variedades lingüísticas. In J. L. C. T. Ceccantini \& R. F. Pereira (Eds.), Cadernos de formação: Língua portuguesa (pp. 47-60). São Paulo, SP: Prograd/ UNESP.

Candau, V. M. (2001). Direitos humanos, violência e cotidiano escolar. In V. M. Candau (Ed.), Reinventar a escola (2. ed., pp. 137-166). Petrópolis, RJ: Vozes.

Colombier, C. (1989). Da violência selvagem à violência simbólica In C. Colombier, G. Mangel \& M. Perdriault. A violência na escola (pp. 87-105). São Paulo, SP: Summus.

Conselho Regional de Psicologia. 6 a região. (2000). Degradação social faz violência crescer no país. Jornal de Psicologia, São Paulo, 10.

El-Moor, P. D., \& Batista, A. S. (1999). Violência e agressão. In W. Codo (Ed.), Educação: Carinho e trabalho (pp. 139-160). Petrópolis, RJ: Vozes.

Fernandes, D. N. et al. (1999). Violência na escola (Relatórios Internos do Departamento de Matemática UNESP - Rio Claro). Rio Claro, SP: Editora da Universidade Estadual Paulista.

Ferreira, A. B. H. (1999). Novo Aurélio século XXI: O dicionário da língua portuguesa (3. ed.). Rio de Janeiro, RJ: Nova Fronteira.

Fraser, M. T. D. (2001). Delinqüência infanto-juvenil e culpa. In U. T. Peres (Ed.), Culpa (pp. 95-103). São Paulo, SP: Escuta.

Freire, P. (1996). Pedagogia da autonomia: Saberes necessários à prática educativa (6. ed.). São Paulo, SP: Paz e Terra.

Itani, A. (1998). A violência no imaginário dos agentes educativos. Cadernos Cedes, Campinas, 47(19), 36-50.

Kehl, M. R. (2001). Radicais, raciais, racionais: A grande fratria do rap na periferia de São Paulo. Revista São Paulo em Perspectiva, 3(13), 95-106.

Martín-Baró, I. (1997) Violencia y agresión social. In I. Martín-Baró. Accion e ideología. Psicologia social desde Centroamérica $(8$. ed., pp. 359-422). San Salvador, El Salvador: UCA. (Original publicado em 1983)

Medrado, H. I. P. (1998). Formas contemporâneas de negociação com a depredação. Cadernos Cedes, Campinas, 47(19), 81-103.

Monteiro, S. A. I. (1998). Tentando compreender Prometeu e Dionísio na mira da violência. Cadernos Cedes, Campinas, 47(19), 67-80.

Njaine, K., \& Minayo, M. C. S. (2003). Violência na escola: Identificando pistas para a prevenção. Interface: Comunicação, Saúde, Educação, Botucatu, 13(7), 119-34.

Passetti, E. (Ed.). (1995). Violentados: Crianças, adolescentes e justiça. São Paulo, SP: Imaginário.

Perdriault, M. (1989). Contra as paredes, a palavra. In C. Colombier, G. Mangel \& M. Perdriault. A violência na escola (pp. 43-86). São Paulo, SP: Summus.

Pinto, R. M., \& Batista, A. S. (1999). Segurança nas escolas e burnout dos professores. In W. Codo (Ed.), Educação: Carinho e trabalho (pp. 312-323). Petrópolis, RJ: Vozes.

Porto, M. R. S., \& Teixeira, M. C. S. (1998). Violência, insegurança e imaginário do medo. Cadernos Cedes, Campinas, 47(19), 51-66.

Reyzábal, M. V. (2003). A comunicação oral como agente educativo eficaz: A comunicação oral e a escrita no processo educacional. In M. Silva (Ed.), Cadernos de Formação-Didática (pp. 2558). São Paulo, SP: Prograd/UNESP. 
Oliveira, É.C.S.; Martins, S.T.F. "Violência, sociedade e escola: da recusa do diálogo à falência da palavra"

Rocha, R. L. M. (2001). Uma cultura da violência na cidade? Rupturas, estetizações e reordenações. Revista São Paulo em Perspectiva, 3(13), 85-94.

Russ, J. (1994). Dicionário de Filosofia. São Paulo, SP: Scipione.

Saffioti, H. I. B. (1989). A síndrome do pequeno poder. In M. A. Azevedo \& V.N. A. Guerra (Eds.), Crianças vitimizadas: A síndrome do pequeno poder (pp. 13-21). São Paulo, SP: Iglu.

Sposito, M. P. (2001). Um breve balanço da pesquisa sobre violência escolar no Brasil. Educação e Pesquisa, 1(27), 87-103.

Teixeira, M. L. T. (1999, jul./ago.). Delito de adolescentes: Não há neutralidade possível. Jornal de Psicologia, São Paulo, pp. 9. Opinião.

Zaluar, A. (2000). Um debate disperso: Violência e crime no Brasil da redemocratização. Revista São Paulo em Perspectiva, 3(13), 03-17.

Érika Cecília Soares Oliveira é psicóloga, mestre pelo Programa de Pós-Graduação em

Educação para a Ciência, Universidade Estadual Paulista - UNESP - Bauru.

oliverikbr@yahoo.com.br
Sueli Terezinha Ferreira Martins é psicóloga, doutora em Psicologia Social pela Pontifícia Universidade Católica de São Paulo - PUCSP. Docente do Departamento de Neurologia e Psiquiatria, UNESP - Botucatu e do Programa de Pós-Graduação em Educação para a Ciência, UNESP - Bauru. Endereço para correspondência: UNESP (Campus de Botucatu) - Rubião Júnior, Caixa Postal 540, CEP 18618-970 - Botucatu, SP. stfm@fmb.unesp.br

\section{Violência, Sociedade e Escola}

Érika Cecília Soares Oliveira e Sueli Terezinha Ferreira Martins Recebido: 30/03/2006

$1^{\text {a }}$ revisão: $20 / 08 / 2006$

Aceite final: 20/10/2006 